\title{
Current practice of stress ulcer prophylaxis in a surgical patient cohort in a German university hospital
}

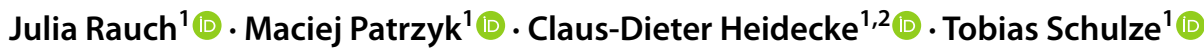

Received: 3 April 2021 / Accepted: 5 September 2021

(c) The Author(s) 2021

\begin{abstract}
Introduction Stress ulcer prophylaxis (SUP) has been a widespread practice both in intensive care units (ICU) and internal wards at the beginning of the twenty-first century. Clinical data suggests an important overuse of acid suppressive therapy (AST) for this indication. Data on current clinical practice of SUP in surgical patients in a non-ICU setting are spares. In the light of a growing number of reports on serious side effects of AST, this study evaluates the use of AST for SUP in a normal surgical ward in a German university hospital.

Methods Between January 2016 and June 2016, SUP was analysed retrospectively in 1132 consecutive patients of the Department of Surgery of the Universitätsmedizin Greifswald.

Results The patients managed with and without SUP were similar with respect to demographic data and treatment with anticoagulants, SSRI and glucocorticoids. Patients with SUP were treated more frequently by cyclooxygenase inhibiting drugs (NSAID, COX2-inhibitors), were more frequently treated in the intermediated care unit and had a longer hospital stay. Risk factors for the development of stress ulcers were similarly present in patient groups managed with and without SUP. About $85.7-99.6 \%$ of patients were given SUP without an adequate risk for stress ulcer development, depending on the method used for risk assessment.

Discussion Still today, SUP is widely overused in non-ICU surgical patients. Information campaigns on risk factors for stress ulcer development and standard operating procedures for SUP are required to limit potential side effects and increased treatment costs.
\end{abstract}

Keywords Stress ulcer $\cdot$ Antacids $\cdot$ Perioperative care $\cdot$ Stress ulcer prophylaxis

\section{Introduction}

The occurrence of upper intestinal bleeding in seriously ill surgical patients has been initially reported more than 150 years ago [1]. The incidence of stress ulcer disease varied over the time and with the patient population considered. With the broad introduction of fibrotic endoscopy in clinical medicine in the 1970s, the presence of gastric mucosal lesions was detected in up to $100 \%$ of severely injured patients, resulting in clinically significant bleeding in $22 \%$ of

Tobias Schulze

tobias.schulze@med.uni-greifswald.de

1 Department of General Surgery, Visceral, Thoracic and Vascular Surgery, Universitätsmedizin Greifswald, Ferdinand-Sauerbruch-Straße, 17475 Greifswald, Germany

2 Present Address: IQTIG - Institut für Qualitätssicherung und Transparenz im Gesundheitswesen, Berlin, Germany this population [2]. This is in accordance with the incidence of overt gastrointestinal (GI) bleeding in up to $25 \%$ of intensive care unit patients reported in 1978 by Hastings et al. [3]. Mortality from gastroduodenal ulceration in this setting was reported to be as high as 58\% in this decade [4]. The high incidence and the potentially live threatening consequences of this condition resulted in the development of various pharmacological measures aiming at the prevention of stress ulcer disease. While antacids were the mainstay of pharmacologic treatment in the mid-twentieth century, a highly effective medical treatment became available with introduction of H2-receptor antagonists (H2RA) in 1978 and of the proton pump inhibitors (PPI) in 1988 [5]. In the light of the potentially severe sequel of stress-induced ulcer disease, use of pharmacologic stress ulcer prophylaxis was a routine treatment in the majority of intensive care units at the beginning of the twenty-first century [6]. At this time, clinically important GI bleeding occurred in 3.5\% of ICU patients, 
resulting in a 20-30\% increase of mortality [7]. During the following years, diagnostic and therapeutic options and the process of care in intensive medicine further improved [8, 9] resulting in decreased incidence of GI bleeding in this patient population. In 2015, an international 7-day inception cohort study found an episode of clinically important GI bleeding in $2.7 \%$ of ICU patients, and the 90-day mortality was not increased in the confounder-adjusted analysis [10].

In contrast, stress ulcer formation with consecutive GI bleeding outside of the ICU setting appears to be a rare event, occurring in $0.26-0.27 \%$ of non-ICU medical patients [11]. Notwithstanding this fact, the current practice of pharmacological SUP in the ICU population has been largely extrapolated to non-critical ill patients in non-ICU wards and in skilled nursing facilities. Thus, up to $88.5 \%$ of patients in internal medicine wards and $65.3 \%$ of long-term care residents on AST for SUP receive these medications without reproducible indication $[12,13]$. While many investigators confirm this observation in internal medicine and general medicine patients [12, 14-18], data on the incidence of inappropriate use of AST for SUP in surgical patients is sparse. A literature search revealed only two publications reporting on this issue. Bez et al. found that of all patients receiving AST for SUP in a general surgery ward, $79 \%$ presented no risk factors for stress ulcers [19]. Parente et al. described an inappropriate use of AST for SUP in 67\% of surgical patients, an incidence comparable to an internal medicine cohort considered in the same study [20]. Growing concerns on potentially severe side effect of AST [21,22] challenge the reported practice of SUP in non-ICU surgical patients. The present work addresses the question whether more than 30 years of ongoing controversy on the adequacy of SUP in this patient population [23] has elicited a modification of clinical practice in the Department of General Surgery, Visceral, Thoracic and Vascular Surgery of the University Medical Centre in the north of Germany.

\section{Materials and methods}

\section{Setting, data collection and patients}

In this retrospective observational study, data was collected from 1132 consecutive patients aged $>18$ years admitted to the Department of General Surgery, Visceral, Thoracic and Vascular Surgery between January 2016 and June 2016 was performed. The study design was approved by the clinical ethics committee of the Universitätsmedizin Greifswald. Patients admitted to the hospital for peptic ulcer disease and gastritis, those who were primarily admitted to the ICU and those who were admitted to the ICU during the stay in the hospital were excluded from the analysis. Patient admitted twice or more frequently were not re-included. Patients with other documented indications for perioperative de novo AST administration were as well excluded from the study (Fig. 1).

Data was collected from the paper-based patient records using a computer-based access form and included demographic data; data concerning previous illnesses including personal history of gastrointestinal bleeding, ulcer disease, GERD and dyspepsia; data concerning the motif for the present admission; treatment-associated data; information on gastrointestinal bleeding episodes during the hospital stay and medication during hospitalisation and prescribed in the hospital discharge letter. Detailed information on AST started during the index admission were retrieved, including the type of medication, the setting of prescription (intermediate care/normal care ward), the moment of prescription (preoperative/postoperative) and the duration of AST administration. Patients discharged with AST were contacted by letter in order to evaluate the duration AST prescribed in the discharge letter. Data for the evaluation of the individual bleeding risk were chosen according to the literature [11, 19, 24, 25].

\section{Risk evaluation}

In order to evaluate the individual risk for gastrointestinal bleeding, six risk constellations for gastrointestinal bleeding were defined according to the current literature [24, 25]: risk constellation 1, antiplatelet agent combined with one of the factors such as age $>60$ years, systemic glucocorticoids, personal history of ulcer disease or severe systemic disease (ASA $\geq 3$ ); risk constellation 2, anticoagulant medication combined with $\geq 2$ of the risk factors listed above; risk constellation 3, combination of at least two anticoagulant or antiplatelet agents; risk constellation 4, long-term therapy with NSAID; risk constellation 5, combination of serotonin reuptake inhibitors with NSAID or COX inhibitors; and risk constellation 6, combination of COX inhibitors with anticoagulants or antiplatelet agents. Pharmacological stress ulcer prophylaxis was considered indicated when at least one risk factor as described above was present. Alternatively, risk factors were defined as done by Bez et al. [19]. Presence of one risk factor according to Bez was considered as justifying pharmacological SUP. Finally, the clinical risk scoring system for nosocomial bleeding (CRSSNB) developed by Herzig et al. was used to determine the risk for a bleeding episode as described by the authors [11]. Risk groups for gastrointestinal bleeding were defined as previously reported [11]. A CRSSNB $\geq 10$ was considered as indication for SUP [11].

\section{Statistical analysis}

Categorical variables are described using frequency. Continuous variables are described using the non-parametric 
Fig. 1 Study population

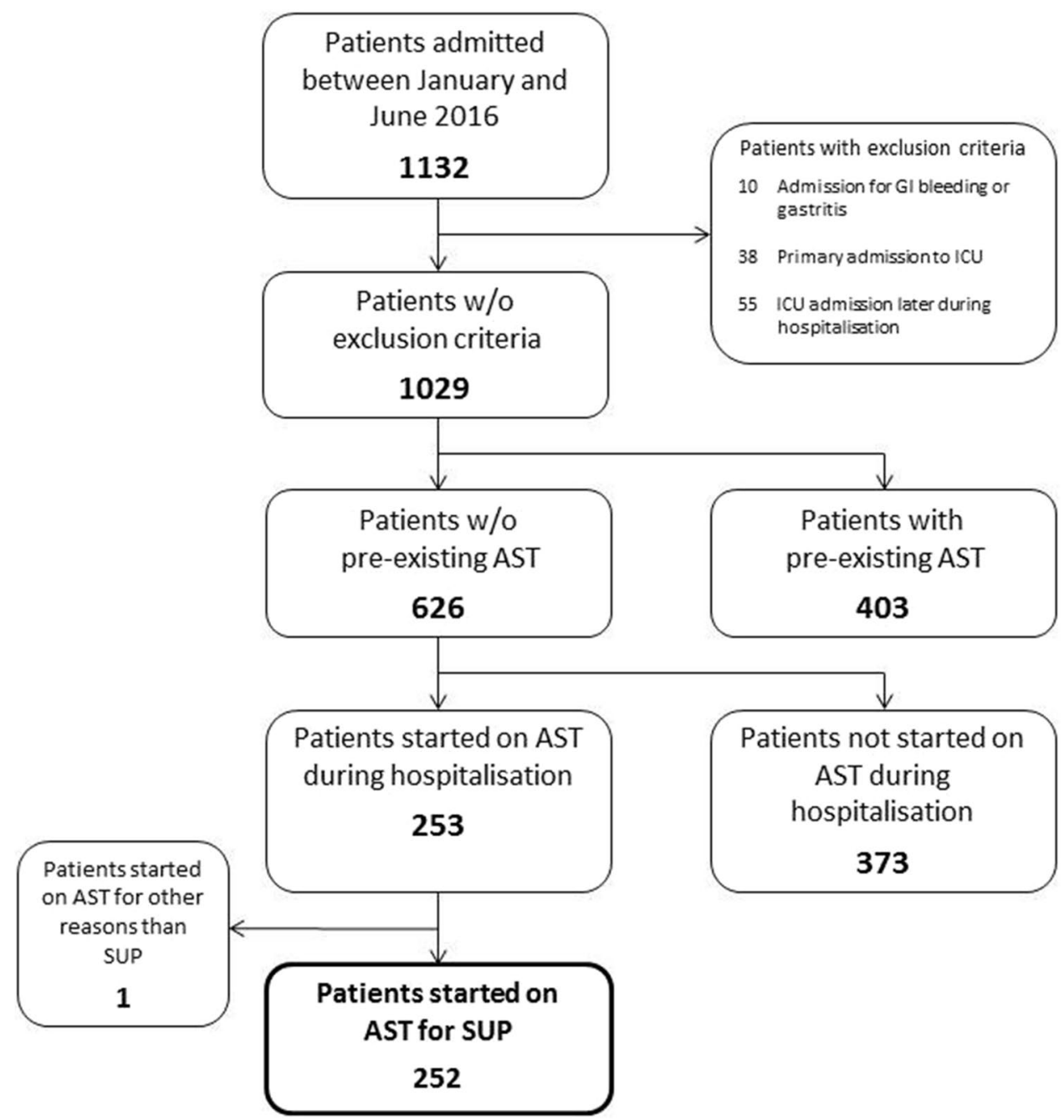

measures median and interquartile range. For the comparison of categorical variables, chi-square tests were applied; for small data, the Fischer's exact test was used. For the continuous variables, the t-test was used after verification of Gaussian distribution by the Kolmogorov-Smirnov test. If the variables showed no Gaussian distribution, the Mann-Whitney test was applied. Statistical analysis was conducted using SPSS software version 25.0 (IBM Inc., Armonk, NY).

\section{Results}

\section{Study population}

Of the 1132 patients admitted to the Department of General, Visceral, Thoracic and Vascular Surgery of the University Medicine Greifswald during the study period, 103 patients presented exclusion criteria including admission for gastritis or GI bleeding, primary admission to the ICU or ICU admission later during the index hospitalisation (Fig. 1). Among the remaining 1029 patients without exclusion criteria, 403 patients had AST listed in their home medication. Of the 626 patients admitted to the hospital without preexisting AST, 252 patients were started on SUP; one further patient was given AST for other indications during the hospital stay. Three hundred seventy-three patients received no SUP during their stay in the hospital.

\section{Demographic and treatment characteristics of patients with and without SUP during hospitalisation}

Table 1 shows demographic data and home medication of the patients admitted to the hospital without pre-existing AST. The patient group started on SUP after admission was compared with those patients managed without SUP. Both patient groups were similar with respect to age, sex and body mass index. Patients with SUP had a tendency towards higher ASA levels; however, this difference was 
Table 1 Demographic data of patients admitted to the hospital without previous acid suppressive medication. Patients being started on SUP during hospitalisation are compared to those without SUP. ASA

\begin{tabular}{|c|c|c|c|}
\hline & $\begin{array}{l}\text { Patients admitted to the hospital without ASM with } \\
\text { SUP during hospitalisation }(n=252)\end{array}$ & $\begin{array}{l}\text { Patients admitted to the hospital without ASM without } \\
\text { SUP during hospitalisation }(n=373)\end{array}$ & $p$ \\
\hline \multicolumn{4}{|l|}{ Age } \\
\hline Mean \pm SD & $56.6 \pm 16.5$ & $53.8 \pm 17.2$ & 0.43 \\
\hline \multicolumn{4}{|l|}{ Sex } \\
\hline Male $(\%)$ & $139(55.2)$ & $226(60.6)$ & 0.19 \\
\hline Female $(\%)$ & $113(44.8)$ & $147(39.4)$ & \\
\hline $\mathrm{BMI} \pm \mathrm{SD}$ & $27.6 \pm 5.7$ & $28.0 \pm 6.1$ & 0.71 \\
\hline \multicolumn{4}{|l|}{ ASA } \\
\hline I & $39(15.5)$ & $66(17.7)$ & \\
\hline II & $132(52.4)$ & $218(58.4)$ & 0.05 \\
\hline III & $75(29.8)$ & $87(23.3)$ & \\
\hline IV & $6(2.4)$ & $2(0.5)$ & \\
\hline \multicolumn{4}{|c|}{ Medication at admission to hospital (\%) } \\
\hline \multicolumn{4}{|c|}{ NSAID/COX2-I } \\
\hline NSAID & $3(1.2)$ & $1(0.3)$ & \\
\hline COX2-I & $6(2.4)$ & $1(0.3)$ & 0.02 \\
\hline None & $243(96.4)$ & $371(99.4)$ & \\
\hline \multicolumn{4}{|c|}{ Glucocorticoids } \\
\hline Yes & $6(2.4)$ & $3(0.8)$ & 0.17 \\
\hline No & $246(97.6)$ & $370(99.2)$ & \\
\hline \multicolumn{4}{|l|}{ SSRI } \\
\hline Yes & $13(5.2)$ & $9(2.4)$ & 0.08 \\
\hline No & $239(94.8)$ & $364(97.6)$ & \\
\hline \multicolumn{4}{|c|}{ Anticoagulation when admitted to hospital (\%) } \\
\hline None & $192(76.2)$ & $284(76.1)$ & \\
\hline Plasmatic & $10(4.0)$ & $17(4.6)$ & 0.95 \\
\hline Antiplatelet & $47(18.7)$ & $69(18.5)$ & \\
\hline Both & $3(1.2)$ & $3(0.8)$ & \\
\hline
\end{tabular}

ASA Physical Status Classification System, BMI body mass index, COX1-I = COX2-inhibitors 
Table 2 Treatment data of patients admitted to the hospital without previous acid suppressive medication. Patients being started on SUP during hospitalisation are compared to those without SUP

\begin{tabular}{lll}
\hline & $\begin{array}{l}\text { Patients admitted to the hospital without ASM with } \\
\text { SUP during hospitalisation }(n=252)\end{array}$ & $\begin{array}{l}\text { Patients admitted to the hospital without ASM with- } \\
\text { out SUP during hospitalisation }(n=373)\end{array}$ \\
\hline $\begin{array}{l}\text { Length of hospital stay (days) } \\
\text { Mean } \pm \text { SD }\end{array}$ & $8.3 \pm 10.5$ & $3.0 \pm 3.8$ \\
Stay in the intermediate care unit $(\%)$ & \\
Yes & $165(65.5)$ & $31(8.3)$ \\
No & $87(34.5)$ & $342(91.7)$ \\
Specialty (\%) & $35(13.9)$ & $128(34.3)$ \\
General surgery & $118(46.8)$ & $168(45.0)$ \\
Visceral surgery & $59(23.4)$ & $23(6.2)$ \\
Thoracic surgery & $39(15.5)$ & $54(14.5)$ \\
Vascular surgery & & 60.05 \\
Therapy (\%) & $27(10.9)$ & $41(11.1)$ \\
Conservative & $23(9.3)$ & $270(72.8)$ \\
Interventional & $198(79.8)$ & \\
Surgical & & \\
\hline
\end{tabular}

Table 3 Diagnosis at discharge of patients admitted to the hospital without previous acid suppressive medication. Patients being started on SUP during hospitalisation are compared to those without SUP. Diagnoses were classified into "thoracic pathologies", "vascular pathologies", "visceral pathologies and pathologies concerning the abdominal wall" as well as "others". Frequencies were compared between patients with and without SUP. Detailed diagnostic information within the diagnostic groups is shown in supplementary table 1

\begin{tabular}{lll}
\hline & $\begin{array}{l}\text { Patients admitted to the hospital without ASM } \\
\text { with SUP during hospitalisation }(n=252)\end{array}$ & $\begin{array}{l}\text { Patients admitted to the hospital without ASM } \\
\text { without SUP during hospitalisation }(n=373)\end{array}$ \\
\hline $\begin{array}{l}\text { Thoracic pathologies } \\
\text { Vascular pathologies }\end{array}$ & $59(23.4)$ & $23(6.2)$ \\
$\begin{array}{l}\text { Visceral pathologies/pathologies } \\
\text { of the abdominal wall }\end{array}$ & $39(15.5)$ & $54(14.5)$ \\
$\begin{array}{l}\text { Others } \\
\text { The }\end{array}$ & $5(2.0)$ & $295(79.1)$ \\
\end{tabular}

\section{Risk for the development of stress ulcer disease and upper GI bleeding in patients without pre-existing AST}

Based on the presence of individual risk factors in combination with concurrent risk medication, six risk constellations for gastrointestinal bleeding were defined according to the current literature [24, 25]. Interestingly, none of these risk constellations were present in the majority of patients both started or not on SUP (85.7\% versus $90.3 \%$ ) (Table 4). Only 35 patients among those with SUP and 36 patients among those without SUP had one risk constellation (with SUP: 13.9\% versus without SUP: 9.7\%). One patient presented more than one risk constellation in the patient group with SUP (with SUP: $0.4 \%$ versus without SUP: $0.0 \%$ ). These differences were not statistically significant $(p=0.12)$.

In 1998, several risk factors for nosocomial gastrointestinal bleeding were identified and published by the American Society of Health-System Pharmacist in patients hospitalised in the ICU $[19,26]$. As expected in the nonICU setting considered in this study, none of these risk factors were present in the majority of patients both in the group with and without SUP (94.4\% versus $96.5 \%$, respectively). One risk factor was present in 13 patients in each group (with SUP: $5.2 \%$ and without SUP: $3.5 \%$ ). Only one patient had more than 1 risk factor, and this patient received SUP. The differences between the groups were not statistically significant.

Herzig et al. developed a scoring system for gastrointestinal bleeding in non-critically ill patients. Depending on the presence of individual risk factors, a maximum score of 12 points for the highest risk represents the highest risk for nosocomial bleeding. The authors consider a risk score of at least 10 to be an acceptable indication for the initiation of SUP [11]. Only one patient in the group with SUP reached a risk score of $10(0.4 \%)$. However, patients put on SUP had significantly higher risk scores compared to patients without SUP (Table 4). 
Table 4 Presence or absence of risk factors for gastrointestinal bleeding in patients admitted to the hospital without previous acid suppressive medication. Patients being started on SUP during hospitalisation are compared to those without SUP

\begin{tabular}{lll}
\hline & $\begin{array}{l}\text { Patients admitted to the hospital without ASM with } \\
\text { SUP during hospitalisation }(n=252)\end{array}$ & $\begin{array}{l}\text { Patients admitted to the hospital without ASM without } \\
\text { SUP during hospitalisation }(n=373)\end{array}$ \\
\hline $\begin{array}{l}\text { Number of pharmacological risk factors }(\%) \\
0\end{array}$ & $216(85.7)$ & $337(90.3)$ \\
1 & $35(13.9)$ & $36(9.7)$ \\
2 & $1(0.4)$ & 0 \\
3 & 0 & 0 \\
4 & 0 & 0 \\
5 & 0 & 0 \\
6 & 0 & 0 \\
Presence of risk factors according to Bez et al & \\
0 & $238(94.4)$ & $360(96.5)$ \\
1 & $13(5.2)$ & $13(3.5)$ \\
$>1$ & $1(0.4)$ & 0 \\
CRSSNB according to Herzig et al & \\
$<6$ & $153(60.7)$ & $270(72.4)$ \\
$\geq 6$ & $76(30.2)$ & $87(23.3)$ \\
$\geq 8$ & $22(8.7)$ & $16(4.3)$ \\
$\geq 10$ & $1(0.4)$ & 0 \\
$\geq 12$ & 0 & 0
\end{tabular}

\section{Gastrointestinal bleeding and esophagogastroduodenoscopy during hospitalisation}

Of those patients without pre-existing AST, only 1 patient developed overt gastrointestinal bleeding $(0.4 \%)$. This patient belonged to the group receiving SUP (Table 5). Upper gastrointestinal tract endoscopy was performed in 9 patients in the group receiving SUP and in 2 patients without SUP. However, suspicion of gastrointestinal bleeding was the indication for only one esophagogastroduodenoscopy in the SUP group (Table 5).

\section{Appropriateness of SUP initiated during hospitalisation}

Among the 252 patients started de novo on AST for SUP during the hospitalisation, the appropriateness of the indication was determined retrospectively. When the decision on the appropriateness of SUP was based on the presence of at least one risk constellation defined as described in materials and methods, initiation of SUP was indicated in 36 patients (14.3\%). In 216 patients (85.7\%), no indication for SUP could be identified based on the above mentioned criteria.

When the criteria for an increased risk of gastrointestinal bleeding under ICU conditions [26] were applied, 14

Table 5 Gastrointestinal bleeding and upper GI tract endoscopy in patients admitted to the hospital without previous acid suppressive medication. Patients being started on SUP during hospitalisation are compared to those without SUP

\begin{tabular}{lll}
\hline & $\begin{array}{l}\text { Patients admitted to the hospital without ASM } \\
\text { with SUP during hospitalisation }(n=252)\end{array}$ & $\begin{array}{l}\text { Patients admitted to the hospital without ASM with- } p \\
\text { out SUP during hospitalisation }(n=373)\end{array}$ \\
\hline $\begin{array}{ll}\text { Gastrointestinal bleeding } \\
\text { Stress-ulcer related }\end{array}$ & $1(0.4)$ & 0 \\
Other reasons & 0 & 0 \\
None & $251(99.6)$ & $373(100)$ \\
Esophagogastroduodenoscopy & \\
For GI bleeding & $1(0.4)$ & 0 \\
For other reasons & $8(3.2)$ & 2 \\
None & $243(96.4)$ & $371(99.5)$ \\
\hline
\end{tabular}


patients $(5.6 \%)$ presented a least 1 risk factor. Conversely, no indication for SUP could be found in 238 patients (94.4\%) based in these criteria.

Finally, when the criteria defined by Herzig et al. were applied, SUP was indicated in only 1 patient in our cohort, corresponding to $0.4 \%$. According to these criteria, no indication could be identified in $99.6 \%$ of patients.

\section{Characteristics of SUP treatment during hospitalisation}

In patients without any reproducible indication for SUP according to the risk constellations defined in the Materials and Methods section, this treatment was started $2.0 \pm 4.2$ days after admission to the hospital. In contrast, in patients presenting an indication, SUP was initiated $4.2 \pm 7.4$ days after admission. Accordingly, in patients receiving SUP with reproducible indication, the first dose of SUP was most frequently administered postoperatively/post-interventionally. In patients without an indication, SUP was started more often pre-operatively/ pre-interventionally than in patients with indication for SUP. In patients requiring transfer to the intermediate care station (165 patients), SUP with reproducible indication was administered significantly more often than in patients without transition to the intermediate care station (29 patients (17.6\%) versus 7 patients $(9.1 \%)$, respectively, $p=0.04)$. In patients admitted to the intermediate care station during the hospitalisation, treatment was discontinued when patients were transferred to the normal ward in 12 patients (8.8\%) of 136 cases where SUP was given without reproducible indication.

The pharmacological group most frequently used for SUP were proton pump inhibitors. There was no difference between the patients receiving SUP with and without reproducible indication (Table 6 ).

\section{Discontinuation of SUP after hospital discharge}

In the majority of patients receiving SUP without reproducible indication, the treatment was discontinued on discharge from hospital (147 patients, 68.1\%). In contrast, in patients with reproducible risk factors during the hospital stay, treatment was discontinued in only $58.3 \%$ (21 patients). However, 12 of the remaining patients of the latter group had risk factors justifying a continued medication with AST. Patients without risk factors and discharged from the hospital with continued AST were interviewed by questionnaire in order to assess whether and when AST was discontinued by the family practitioner (Table 7). From 70 patients contacted, 27 patients returned completed questioners. Only three of them (11.1\%) still continued taking AST after more than 9 months. In the majority of cases, AST was discontinued by the family practitioner 1 to 3 months after discharge from hospital.
Table 6 Pharmacological groups used for SUP. Patient groups receiving SUP with and without reproducible indication were compared. PPI proton pump inhibitors, H2-antagonist histamine receptor 2 antagonist

\begin{tabular}{llll}
\hline & $\begin{array}{l}\text { Patients receiving SUP with repro- } \\
\text { ducible indication }(n=36)\end{array}$ & $\begin{array}{l}\text { Patients receiving SUP without } \\
\text { reproducible indication }(n=216)\end{array}$ & $p$ \\
\hline $\begin{array}{l}\text { Pharmacological group used for SUP (\%) } \\
\text { PPI }\end{array}$ & $33(91.7)$ & $209(96.8)$ & 0.16 \\
H2-antagonist & $3(8.3)$ & $7(3.2)$ & \\
Both sequentially & 0 & 0 & \\
Others & 0 & 0 & \\
\hline
\end{tabular}

Table 7 Time to discontinuation of SUP after discharge from hospital

\begin{tabular}{llll}
\hline & $\begin{array}{l}\text { Patients receiving SUP with } \\
\text { reproducible indication }(n=3)\end{array}$ & $\begin{array}{l}\text { Patients receiving SUP without } \\
\text { reproducible indication }(n=27)\end{array}$ & $p$ \\
\hline Time elapsed until cessation of SUP (\%) & \\
Immediately discontinued & $2(66.6)$ & $7(25.9)$ \\
$<1$ month & 0 & 0 & 0.5 \\
$1-3$ months & 0 & $10(37.0)$ & \\
4-6 months & $1(33.3)$ & $4(14.8)$ & \\
$7-9$ months & 0 & $2(7.4)$ \\
No cessation & 0 & $3(11.1)$ \\
Taken on demand & 0 & $1(3.7)$ & \\
\hline
\end{tabular}




\section{Appropriateness of AST in the pre-existing home medication}

Among the 1029 patients without exclusion criteria, 403 patients $(39.1 \%)$ received AST. Of those, 188 patients $(46.7 \%)$ presented a reproducible indication, while no risk factors or pathologies requiring AST could be identified in 215 patients $(53.3 \%)$. In both groups, AST was maintained in $100 \%$ of patients during the hospitalisation. Interestingly, in those patients without a reproducible indication for AST on admission, this medication was discontinued in $6.5 \%$ of patients on discharge, while it was continued in $93.0 \%$.

\section{Discussion}

Twenty years after the publication of the first report on the over-prescription of AST for the prevention of stress ulcers in non-ICU patients [27], SUP is still a widely used practice in patients on non-ICU surgical wards. Among the patients admitted without pre-existing ASM, 40.3\% received SUP de novo. This is slightly less than the $54 \%$ frequency of newly started ASM in surgical patients found by Bez et al. in 2013 but comparable to that found in a mixed surgical and medical patient cohort described by Parente et al. in 2003 in surgical patients $[19,20]$. In general medical ward patients, ASM for SUP is started de novo on hospital admission in $22.1-84 \%$ $[15,16,18,28,29]$. Thus, the frequency of SUP administration in surgical and internal medicine non-ICU wards seems to occur to a similar extent.

It is important to address the issue of the criteria on which the decision is based to prescribe SUP during hospitalisation. The comparison of patients started on SUP with those who were not showed no significant differences between demographic data of both groups. There was a tendency to higher ASA groups in patients receiving SUP. Pre-existing medication with NSAID/Cox-2 inhibitors was significantly more frequent in patients being started on SUP. However, the overall frequency of this medication was very low. Patients with de novo SUP had higher total days in hospital and required ICU monitoring more frequently than patients without SUP. These findings suggest that treating surgeons provided SUP preferentially to patients with more severe clinical courses. Accordingly, patients started on SUP had higher clinical risk scores for nosocomial GI bleeding than those not started on SUP. However, the absolute risk for gastrointestinal bleeding, as judged by the clinical risk score developed by Herzig, was very low in all but one patient in this study, ranging from 0.1 to $0.68 \%$, not justifying SUP [11]. Our findings indicate that in clinical routine, the relative risk for the development of nosocomial gastrointestinal bleeding in patients on a normal surgical ward is correctly judged by the treating surgeon, while the absolute risk in comparison to the potential side effects of AST is largely overestimated. The usage of clinical risk scores to assess the risk for nosocomial gastrointestinal bleeding could be an appropriate tool to remediate this misjudgement. The low incidence of stress ulcer-associated gastrointestinal bleeding found in our patient cohort suggest that the low risk of stress-induced gastrointestinal bleeding found in a mixed patient cohort on medical and non-medical normal wards also applies to non-critically ill surgical patients [11].

Appropriateness of newly started ASM for SUP during hospital admission has been defined very heterogeneously in publications during the last 20 years [12, 14-20, 28]. In consequence, the comparison of the incidences of inappropriate SUP between various reports is challenging. In surgical patients, SUP without adequate indication is reported in $67.0-72.6 \%$ of patients $[19,20]$. In medical patients, SUP was given without indication to 36.9-100.0\%. [12, 14-18, $28,30]$. According to the only official guideline on stress ulcer prophylaxis published to date, SUP is not recommended in patients outside the ICU [26]. Thus, in a strict interpretation of this recommendation, every stress ulcer prophylaxis initiated in non-ICU wards would be inadequate. However, the authors also state that "the presence of patient risk factors for clinically important bleeding, not just admission to an intensive care unit should determine the need for a stress ulcer prophylaxis". Risk factors can be derived from current recommendations on gastric protection in presence of risk medication [24, 25]. Moreover, risk scores published and validated in the literature can be used to assess the patient risk to develop clinically significant GI bleeding $[11,19]$. Depending on the criteria used to define appropriateness, SUP initiated in the surgical collective in this study was inappropriate in $85.7-99.6 \%$ of patients. Based on the risk score of Herzig et al., the majority of our patients started on SUP (99.6\%) had a risk for clinically significant bleeding of less than $0.7 \%$. In the majority of our patients (risk score $\leq 8$ ), the number of needed-to-treat to prevent a bleeding episode is 500 or higher. This exceeds by far the number needed to harm for nosocomial pneumonia [31]. The application of clinical risk scores may improve the risk assessment for GI bleeding in clinical routine and thus increase the appropriateness of AST use for SUP.

In the current medical literature, there is only little evidence that a specific surgical procedure requires prophylactic SUP in the non-ICU setting. In most cases, the indication for prophylactic SUP results from the risk profile of the patient based on specific medications or co-morbidities. In contrast, in bariatric surgery, prophylactic administration of AST as SUP is a widely approved part of perioperative treatment protocols due to the high frequency of marginal ulcers occurring after this kind of surgery [32-34]. However, prophylactic perioperative use of AST has to be distinguished from the therapeutic perioperative administration of AST 
for the treatment of postoperative functional dyspepsia or manifest gastritis or pre-existing pathologies [35].

In the majority of recent reports as well as in our study, PPI were the most frequently used drug class for SUP [12, $15,17,18,28]$. Although PPI have been considered to be a very safe drug after their introduction to the market, there is increasing controversy concerning potentially severe side effects of these molecules, including bacterial gastroenteritis [22], acute interstitial nephritis [36], vitamin B deficiency [37], community and hospital acquired pneumonia, dementia, osteoporosis and electrolyte disturbances (for review see [21]). There have also been epidemiological reports on long-term PPI use and increased risk of certain cancers, e.g. gastric cancer and pancreatic cancer [38-40]. Even if there is still considerable controversy whether or not the risk increase for certain side effects is sufficiently important to be clinically relevant, a valid indication should be verified before starting PPI administration. This was not the case in the vast majority of patients that have been started on SUP de novo during their hospital admission. Interestingly, the awareness for this problem seems to be more developed in the group of family doctors than in the surgical community, since the majority of non-indicated SUPs not discontinued on discharge were stopped during the 3 months following the end of the hospital stay. This is different from older reports, where ASM started without adequate indication during hospitalisation was still present in $46-79.4 \%$ of patients 3 months after discharge [15, 20].

There is an important fraction of patients admitted to the surgical department already receiving AST prescribed previously by their general practitioner. In our patient cohort, $39.1 \%$ of patients had AST in their home medication. This prevalence is slightly superior to those reported in internal medicine patients $(10.7-33.1 \%)$ [14-16, 18] [12, 28]. Although no indication for this treatment could be determined upon review of the patient charts, AST was continued in virtually all patients during the hospitalisation, and prescription was continued in the discharge letter in the majority of patients (93\%). This indicates that critical appraisal of the indication for this class of medication is not sufficiently developed in order to reduce the wide spread over-prescription of AST. In this setting, pharmacist-driven protocols or participation of pharmacists on ward rounds have been shown to effectively reduce the overuse of AST during and after hospitalisation [41].

In summary, despite the vigorous debate on AST overprescription for SUP led in the current literature, SUP is still widely practised in surgical patients in the non-ICU setting. The official guideline on SUP was published more than 20 years ago, only briefly addresses SUP in the non-ICU setting and advises against routine SUP in adult medical and surgical patients in non-ICU settings [26]. However, various constellations involving risk medications, polypharmacy and multimorbidity require more practicable recommendations on this issue. The development and implementation of local standard operating procedures addressing the issue of SUP as well as pharmacist-driven protocols may be successful tools to reduce the inappropriate overmedication with AST.

Supplementary Information The online version contains supplementary material available at https://doi.org/10.1007/s00423-021-02325-3.

Acknowledgements We thank U. Walschus for statistical counselling.

Authors' contributions Conceptualization: J.R. and T.S. Methodology: J.R. and T.S. Data bank management: J.R. and T.S. Data collection: J.R. Validation: T.S., M.P. and C-D. H. Data analysis: J.R. and T.S. Writing — original draft preparation: J.R. and T.S. Writing—review and editing: M.P. and C.-D.H. Supervision: T.S. All authors have read and agreed to the published version of the manuscript.

Funding Open Access funding enabled and organized by Projekt DEAL.

\section{Declarations}

Ethical approval The study design was approved by the clinical ethics committee of the Universitätsmedizin Greifswald.

Conflict of interest The authors declare no competing interests.

Open Access This article is licensed under a Creative Commons Attribution 4.0 International License, which permits use, sharing, adaptation, distribution and reproduction in any medium or format, as long as you give appropriate credit to the original author(s) and the source, provide a link to the Creative Commons licence, and indicate if changes were made. The images or other third party material in this article are included in the article's Creative Commons licence, unless indicated otherwise in a credit line to the material. If material is not included in the article's Creative Commons licence and your intended use is not permitted by statutory regulation or exceeds the permitted use, you will need to obtain permission directly from the copyright holder. To view a copy of this licence, visit http://creativecommons.org/licenses/by/4.0/.

\section{References}

1. Hubert JP Jr, Kiernan PD, Welch JS, ReMine WH, Beahrs OH (1980) The surgical management of bleeding stress ulcers. Ann Surg 191(6):672-679

2. Czaja AJ, McAlhany JC, Pruitt BA Jr (1974) Acute gastroduodenal disease after thermal injury An endoscopic evaluation of incidence and natural history. N Engl J Med. 291(18):925-929

3. Hastings PR, Skillman JJ, Bushnell LS, Silen W (1978) Antacid titration in the prevention of acute gastrointestinal bleeding: a controlled, randomized trial in 100 critically ill patients. N Engl J Med 298(19):1041-1045

4. Fogelman MJ, Garvey JM (1966) Acute gastroduodenal ulceration incident to surgery and disease. Analysis and review of eightyeight cases. Am J Surg. 112(5):651-656

5. Garnett WR (2003) History of acid suppression: focus on the hospital setting. Pharmacotherapy 23(10 Pt 2):56S-60S

6. Erstad BL, Barletta JF, Jacobi J, Killian AD, Kramer KM, Martin SJ (1999) Survey of stress ulcer prophylaxis. Crit Care 3(6):145-149 
7. Cook DJ, Griffith LE, Walter SD, Guyatt GH, Meade MO, Heyland DK, Kirby A, Tryba M (2001) The attributable mortality and length of intensive care unit stay of clinically important gastrointestinal bleeding in critically ill patients. Crit Care 5(6):368-375

8. Kaukonen KM, Bailey M, Suzuki S, Pilcher D, Bellomo R (2014) Mortality related to severe sepsis and septic shock among critically ill patients in Australia and New Zealand, 2000-2012. JAMA 311(13):1308-1316

9. Citerio G, Bakker J, Bassetti M, Benoit D, Cecconi M, Curtis JR, Hernandez G, Herridge M, Jaber S, Joannidis M, Papazian L, Peters M, Singer P, Smith M, Soares M, Torres A, Vieillard-Baron A, Timsit JF, Azoulay E (2014) Year in review in Intensive Care Medicine 2013: I. Acute kidney injury, ultrasound, hemodynamics, cardiac arrest, transfusion, neurocritical care, and nutrition. Intensive Care Med 40(2):147-159

10. Krag M, Perner A, Wetterslev J, Wise MP, Borthwick M, Bendel S, McArthur C, Cook D, Nielsen N, Pelosi P, Keus F, Guttormsen AB, Moller AD, Moller MH (2015) Stress ulcer prophylaxis in the intensive care unit: an international survey of 97 units in 11 countries. Acta Anaesthesiol Scand 59(5):576-585

11. Herzig SJ, Rothberg MB, Feinbloom DB, Howell MD, Ho KK, Ngo LH, Marcantonio ER (2013) Risk factors for nosocomial gastrointestinal bleeding and use of acid-suppressive medication in non-critically ill patients. J Gen Intern Med 28(5):683-690

12. Hong MT, Monye LC, Seifert CF (2015) Acid suppressive therapy for stress ulcer prophylaxis in noncritically ill patients. Ann Pharmacother 49(9):1004-1008

13. Patterson Burdsall D, Flores HC, Krueger J, Garretson S, Gorbien MJ, Iacch A, Dobbs V, Homa T (2013) Use of proton pump inhibitors with lack of diagnostic indications in 22 Midwestern US skilled nursing facilities. J Am Med Dir Assoc 14(6):429-432

14. Nardino RJ, Vender RJ, Herbert PN (2000) Overuse of acidsuppressive therapy in hospitalized patients. Am J Gastroenterol 95(11):3118-3122

15. Zink DA, Pohlman M, Barnes M, Cannon ME (2005) Long-term use of acid suppression started inappropriately during hospitalization. Aliment Pharmacol Ther 21(10):1203-1209

16. Pham CQ, Regal RE, Bostwick TR, Knauf KS (2006) Acid suppressive therapy use on an inpatient internal medicine service. Ann Pharmacother 40(7-8):1261-1266

17. Scagliarini R, Magnani E, Pratico A, Bocchini R, Sambo P, Pazzi $P$ (2005) Inadequate use of acid-suppressive therapy in hospitalized patients and its implications for general practice. Dig Dis Sci 50(12):2307-2311

18. Sheikh-Taha M, Alaeddine S, Nassif J (2012) Use of acid suppressive therapy in hospitalized non-critically ill patients. World 3(6):93-96

19. Bez C, Perrottet N, Zingg T, Leung Ki EL, Demartines N, Pannatier A (2013) Stress ulcer prophylaxis in non-critically ill patients: a prospective evaluation of current practice in a general surgery department. J Eval Clin Pract 19(2):374-378

20. Parente F, Cucino C, Gallus S, Bargiggia S, Greco S, Pastore L, Bianchi PG (2003) Hospital use of acid-suppressive medications and its fall-out on prescribing in general practice: a 1-month survey. Aliment Pharmacol Ther 17(12):1503-1506

21. Malfertheiner P, Kandulski A, Venerito M (2017) Proton-pump inhibitors: understanding the complications and risks. Nat Rev Gastroenterol Hepatol 14(12):697-710

22. Wei L, Ratnayake L, Phillips G, McGuigan CC, Morant SV, Flynn RW, Mackenzie IS, MacDonald TM (2017) Acid-suppression medications and bacterial gastroenteritis: a population-based cohort study. Br J Clin Pharmacol 83(6):1298-1308

23. Geroulanos S, Attinger B, Decurtins M (1990) Buchmann P [Nosocomial lung infections. Epidemiology and problems of stress ulcer prevention]. Langenbecks Arch Chir Suppl II Verh Dtsch Ges Chir 8:1063-1068
24. Fischbach W, Darius H, Gross M, Koop H, Kruck I, Petersen KU (2010) Concomitant use of platelet aggregation inhibitors and proton pump inhibitors (PPIs): position paper of the German Society for Digestive and Metabolic Diseases (DGVS) and the German Society of Cardiology (DGK). Z Gastroenterol 48(9):1156-1163

25. Fischbach W, Malfertheiner P, Lynen Jansen P, Bolten W, Bornschein J, Buderus S, Glocker E, Hoffmann JC, Koletzko S, Labenz J, Mayerle J, Miehlke S, Mossner J, Peitz U, Prinz C, Selgrad M, Suerbaum S, Venerito M, Vieth M (2016) S2k-guideline Helicobacter pylori and gastroduodenal ulcer disease. Z Gastroenterol 54(4):327-363

26. ASHP (1999) ASHP therapeutic guidelines on stress ulcer prophylaxis. ASHP Commission on Therapeutics and approved by the ASHP Board of Directors on November 14, 1998. Am J Health Syst Pharm 56(4): 347-379

27. Gullotta R, Ferraris L, Cortelezzi C, Minoli G, Prada A, Comin U, Rocca F, Ferrara A, Curzio M (1997) Are we correctly using the inhibitors of gastric acid secretion and cytoprotective drugs? Results of a multicentre study. Ital J Gastroenterol Hepatol 29(4):325-329

28. Heidelbaugh JJ, Inadomi JM (2006) Magnitude and economic impact of inappropriate use of stress ulcer prophylaxis in non-ICU hospitalized patients. Am J Gastroenterol 101(10):2200-2205

29. Gupta R, Garg P, Kottoor R, Munoz JC, Jamal MM, Lambiase LR, Vega KJ (2010) Overuse of acid suppression therapy in hospitalized patients. South Med J 103(3):207-211

30. Walker NM, McDonald J (2001) An evaluation of the use of proton pump inhibitors. Pharm World Sci 23(3):116-117

31. Herzig SJ, Howell MD, Ngo LH, Marcantonio ER (2009) Acidsuppressive medication use and the risk for hospital-acquired pneumonia. JAMA 301(20):2120-2128

32. Ying VW, Kim SH, Khan KJ, Farrokhyar F, D’Souza J, Gmora S, Anvari M, Hong D (2015) Prophylactic PPI help reduce marginal ulcers after gastric bypass surgery: a systematic review and metaanalysis of cohort studies. Surg Endosc 29(5):1018-1023

33. Gumbs AA, Duffy AJ, Bell RL (2006) Incidence and management of marginal ulceration after laparoscopic Roux-Y gastric bypass. Surg Obes Relat Dis 2(4):460-463

34. Contival N, Menahem B, Gautier T, Le Roux Y, Alves A (2018) Guiding the non-bariatric surgeon through complications of bariatric surgery. J Visc Surg 155(1):27-40

35. Savarino V, Dulbecco P, de Bortoli N, Ottonello A, Savarino E (2017) The appropriate use of proton pump inhibitors (PPIs): need for a reappraisal. Eur J Intern Med 37:19-24

36. Arora P, Gupta A, Golzy M, Patel N, Carter RL, Jalal K, Lohr JW (2016) Proton pump inhibitors are associated with increased risk of development of chronic kidney disease. BMC Nephrol 17:112

37. Lam JR, Schneider JL, Zhao W, Corley DA (2013) Proton pump inhibitor and histamine 2 receptor antagonist use and vitamin B12 deficiency. JAMA 310(22):2435-2442

38. Brusselaers N, Wahlin K, Engstrand L, Lagergren J (2017) Maintenance therapy with proton pump inhibitors and risk of gastric cancer: a nationwide population-based cohort study in Sweden. BMJ Open 7(10):e017739

39. Brusselaers N, Sadr-Azodi O, Engstrand L (2020) Long-term proton pump inhibitor usage and the association with pancreatic cancer in Sweden. J Gastroenterol 55(4):453-461

40. Xie Y, Bowe B, Yan Y, Xian H, Li T, Al-Aly Z (2019) Estimates of all cause mortality and cause specific mortality associated with proton pump inhibitors among US veterans: cohort study. BMJ $365: 11580$

41. Mersfelder TL, Jacob C, Lam JK, Kavanaugh KJ, Molnar CM (2019) Evaluation of a pharmacist-driven protocol to reduce inappropriate use of acid-suppressive medications in the non-ICU setting. P 44(8): 471-473.

Publisher's note Springer Nature remains neutral with regard to jurisdictional claims in published maps and institutional affiliations. 